\title{
Evaluation of thermal properties of MMCp composites with silver alloy matrix
}

\author{
Jakub Wieczorek $^{1} \cdot$ Tomasz Maciąg $^{2} \cdot$ Karolina Kowalczyk $^{1} \cdot$ Damian Migas $^{1}[$
}

Received: 25 August 2019 / Accepted: 23 April 2020 / Published online: 13 May 2020

(c) The Author(s) 2020

\begin{abstract}
Silver, silver alloys, and composites with silver matrix are used mainly as electric contacts, circuit-breakers, and slide bearings. Contacts working conditions require as high as possible thermal and electrical conductivity, wear resistance during electric arc work, low susceptibility to tacking, and chemical stability. Unreinforced silver alloys do not meet those expectations, hence increasing interest in metal matrix composites. Reinforcing with ceramic particles improves tribological wear resistance and minimizes formability of silver alloys. At the same time, introduction of ceramic particles decreases thermal and electrical conductivity. In this paper, manufacturing method of silver-based composites reinforced with particles $\mathrm{Al}_{2} \mathrm{O}_{3}$, $\mathrm{SiC}$, and glassy carbon was described. Composites were subjected to differential thermal analysis. Furthermore, thermal diffusivity measurements using laser flash method, as well as measurements of linear thermal expansion coefficient using dilatometric method were performed in order to determine heat conductivity of the prepared composites.
\end{abstract}

Keywords Thermal analysis $\cdot$ MMCP $\cdot$ Composites $\cdot$ Silver matrix $\cdot$ Suspension method

\section{Introduction}

The application of metal matrix composites (MMCs) is common in industry [1-4]. Composites based on light metal alloys (aluminum, magnesium) are used in automotive and aerospace industries owing to their low density and simple manufacturing methods [5-7]. Composites based on nickel characterized by high-temperature creep and corrosion resistance are broadly used in space technology and aviation $[8,9]$. Zinc- and lead-based composites have good sliding properties and abrasion resistance [4, 10]. Additionally, composites based on silver and copper are used as a contacts in electronics and electrotechnics due to high thermal and electrical conductivity. Furthermore, the Ag-and $\mathrm{Cu}$-based

Tomasz Maciąg

tomasz.maciag@polsl.pl

Damian Migas

damian.migas@polsl.pl

1 Department of Advanced Materials and Technologies, Silesian University of Technology, Krasińskiego 8 st., 40-019 Katowice, Poland

2 Department of Metallurgy and Recycling, Silesian University of Technology, Krasińskiego 8 st., 40-019 Katowice, Poland composites are utilized as conductive elements, junctions or terminals $[3,11,12]$.

A material dedicated for electric contacts should not change properties after numerous connections, after longer shut-down breaks, and during ongoing current passing. At the same time, it should by characterized by high thermal and electric conductivity preventing from excessive temperature rise in contacts, as well as by high melting temperature ensuring material resistance to welding and tacking [13]. Pure silver has the highest thermal and electrical conductivity and the lowest contact resistance among all metals. Due to significant workability and susceptibility to corrosion caused by sulfur oxides from the atmosphere, silver alloys are applied in industry. Alloying additions such as copper, zinc, manganese, cadmium, nickel, and aluminum increase endurance, wear resistance, sparking resistance, and corrosion resistance of silver alloys [13]. Nevertheless, those materials are susceptible to electric arc, erosion, and have poor weighting strain resistance. In order to improve those properties, reinforcing particles may be introduced into the alloy in a shape of pure elements, carbides or oxides, obtaining in this way MMCp composites with silver alloy matrix [14]. Reinforcing with particles has advantageous impact on hardness, resistance to adhesive and tribological wear, however, it decreases 
thermal and electrical conductivity, which results from higher electrical resistance of reinforcement material.

Manufacturing technologies of metal composite materials are mostly based on casting methods and powder metallurgy [3, 4, 15-17]. Among casting methods, there is gravity, pressure or centrifugal casting. Production of composites using liquid-phase methods has some disadvantages, including the presence of undesirable physicochemical phenomena between reinforcement and matrix, poor wettability, and reinforcing phase segregation. A boundary layer of different composition and properties compared to that of individual composite components is formed in the area of contact between reinforcement and metal matrix. Such phenomenon occurs due to the fact that the layer next to matrix and reinforcement is the main structural element of composites. Thickness of this layer and physicochemical nature may have influence on properties of matrix - reinforcement joint, whereas quality and properties of this joint determines properties of obtained composite. Boundary layer affects composite destruction mechanism [18, 19]. A wettability effect of reinforcing phase through liquid metal, apart from distinct impact on quality of components connection of the composite, influences on possibility of composites manufacturing using low-pressure and gravity methods. A requisite condition of creation of suspended solids in liquid matrix is a particle submersion. A homogenous distribution of particles in a liquid phase is vital for creation of a stable system. As a result of insufficient wettability, a separation of reinforcing phase from liquid metal may occur, leading to floating of particles to the surface. This adverse effect enhances with a decrease in size of particles [19]. Additionally, a reinforcing phase is segregated, and creates clusters, which are a result of various processes affecting reinforcing particles before their introduction, as well as forces from the inside of the system: solid phase-liquid metal. The area consisting of single particles contacting each other with surfaces or peaks is called agglomerate [18].

Based on the research on technologies of metal composites manufacturing, authors, in this work, applied suspension method that is combination of casting and mixing method [14, 17, 20, 21]. For the research, MMCp composites with silver alloy matrix reinforced with $\mathrm{Al}_{2} \mathrm{O}_{3}$, $\mathrm{SiC}$, and glassy carbon particles were prepared. Composites were extruded on KOBO press. As a result of extrusion, final forming of composite structure with expected endurance and applicable properties occurs. Differential thermal analysis (DTA) was performed in order to determine the influence of reinforcement on temperature of transformations occurring in the composite. Values of thermal expansion coefficient were determined as well, using measurements of thermal diffusivity and thermal expansion.

\section{Experimental}

Initial research and the literature studies proved that it is impossible to create stable suspended ceramic particles such as $\mathrm{Al}_{2} \mathrm{O}_{3}$ and $\mathrm{SiC}$ in pure silver due to insufficient wettability of ceramic particles by liquid silver matrix $[22,23]$. In order to resolve this obstacle, techniques of a reinforcement preparation based on change of chemical composition of matrix alloy in order to lower its contact tension in liquid phase were applied. The analysis of equilibrium system of silver alloys enabled to select silver alloy with magnesium as a modification [24]. In order to secure effective wetting by liquid matrix of reinforcing particles before introducing to silver alloy, reinforcement was subjected to surface preparation by creating a composite master alloy. The process was conducted under protective atmosphere of argon, in resistance furnace, by using mixing method with graphite stirrer. Aluminum alloys with $20 \%$ magnesium may easily wet ceramic particles $\mathrm{Al}_{2} \mathrm{O}_{3}$ and $\mathrm{SiC}$, therefore, such alloy was used in this experiment. Substantial fraction of magnesium in alloy matrix enabled introduction of reinforcing particles of around $60 \%$ vol. The obtained alloy was casted on cast iron board and after cooling, it was crushed to pieces of $5 \mathrm{~mm}$ diameter. Subsequently, master alloy containing reinforcing particles was introduced to silver alloy in induction furnace. The silver alloy with $2 \%$ silicon was melted in graphite crucible at $1100{ }^{\circ} \mathrm{C}$, furnace was shut-down, and composite master alloy was introduced and mixed using graphite stirrer. Few cycles were performed to reduce the influence of eddy current on suspension motion in a liquid metal, whereas, also enabled introduction of desired quantity of suspension. The obtained composite was casted to graphite mold.

The composite materials after casting were subjected to direct extrusion with KOBO method. From $60 \mathrm{~mm}$ diameter ingots, $12 \mathrm{~mm}$ diameter rods were extruded. During conducted experiment, process parameters allowing obtainment of materials in shape of rods without any surface defects were determined: input temperature of $500{ }^{\circ} \mathrm{C}$, extrusion velocity (piston rod velocity): $2 \mathrm{~mm} \mathrm{~min}^{-1}$, rotation velocity 80 cycles $\mathrm{min}^{-1}$.

Microscopic measurements of microstructure with HITACHI S-3400N scanning electron microscope were performed in high vacuum, using secondary electron (SE) and backscattered electron (BSE). The applied 
accelerating voltage was $15 \mathrm{kV}$. Metallographic specimens were obtained from properly prepared samples cut in lateral direction with respect to material axis.

The differential thermal analysis of the MMCp composites with silver alloy matrix was conducted on thermal analyzer NETZSCH STA 449 Jupiter F3. Measurements were taken in protective atmosphere of argon in alumina crucibles on samples cylinder shaped of $5 \mathrm{~mm}$ diameter and $12 \mathrm{~mm}$ length. The temperature program was based on heating the sample with $10{ }^{\circ} \mathrm{C} \mathrm{min}-1$ velocity up to temperature $900{ }^{\circ} \mathrm{C}$, and cooling velocity of $10{ }^{\circ} \mathrm{C} \mathrm{min}{ }^{-1}$.

The thermal diffusivity was measured using laser flash method, whereas linear coefficient of thermal expansion was determined via dilatometric method in order to further determination of heat conductivity $\lambda$ of the studied composites, based on dependence:

$\lambda(T)=\rho(T) \cdot \alpha(T) \cdot C_{\mathrm{p}}(T)$

where $\rho$-material density, $\alpha$-thermal diffusivity, $C_{\mathrm{p}}$ - specific heat.

Thermal diffusivity was determined using NETZSCH LFA 427 device with following process parameters: sample shaped as ring of $12 \mathrm{~mm}$ diameter and $3 \mathrm{~mm}$ height, initial temperature $20^{\circ} \mathrm{C}$, voltage $450 \mathrm{~V}$, pulse time $0.6 \mathrm{~ms}$, argon flow $50 \mathrm{~mL} \mathrm{~min}{ }^{-1}$. The measurements of linear coefficient of thermal expansion were made on NETZSCH DIL 402C device. Process parameters were as follows: sample shaped as cylinder of $6 \mathrm{~mm}$ diameter and $20 \mathrm{~mm}$ length, initial temperature $40^{\circ} \mathrm{C}$, maximum temperature $650{ }^{\circ} \mathrm{C}$ heating velocity $5^{\circ} \mathrm{C} \mathrm{min}{ }^{-1}$, argon flow $50 \mathrm{~mL} \mathrm{~min}{ }^{-1}$.

\section{Results}

The phase composition of obtained composites is shown in Table 1. Sample micrographs of microstructures may be seen in Fig. 1. Matrix alloy was homogenous. Only the presence of minor contamination was identified. In the case of composite $\mathrm{Ag} / \mathrm{Al}_{2} \mathrm{O}_{3}$, a homogenous reinforcing phase was obtained in whole volume of the material. In composite $\mathrm{Ag} / \mathrm{SiC}$, a homogenous reinforcing phase was distinguished, however, also a higher concentration of particles was identified in the center part of the samples compared to that of close to the edges. A porosity occurred as well. The composite $\mathrm{Ag} / \mathrm{Gc}$ was characterized with the least homogenous distribution of a reinforcing phase.

A range of thermal stability of composites impacts on a practical aspect of application as electric contacts. With current flow in contacts, a substantial and instantaneous temperature rise occurs on surface that is related to the presence of an electric arc. It might lead to a partial melting of contact surface and as consequence, melting of its junction. Based on DTA thermal analysis, a safe temperature range for thermal work of MMCp composites may be determined.

The results of DTA analysis of MMCp composites with silver alloy matrix are shown in Fig. 2. The melting point of the matrix alloy was $812{ }^{\circ} \mathrm{C}$, and is about $150{ }^{\circ} \mathrm{C}$ lower than melting temperature of pure silver. In the case of $\mathrm{Ag} /$ $\mathrm{SiC}$ composite, on heating curve, two distinct endothermic peaks were identified. The first one, starting at temperature about $400{ }^{\circ} \mathrm{C}$, has no corresponding exothermic peak on cooling curve. This might be related to dissolution of a phase present in the original alloy structure after casting or during plastic work. The second endothermic peak starts at temperature $583{ }^{\circ} \mathrm{C}$, and the corresponding exothermic effect during cooling may be identified at temperature $620^{\circ} \mathrm{C}$. In this case, an apparent phase transition occurs, which requires an additional interpretation. In the composite $\mathrm{Ag} / \mathrm{Al}_{2} \mathrm{O}_{3}$, the distinct exothermic thermal effect accompanying cooling is present. Presumably, it is related to chemical reactions in a phase boundary between reinforcing particles and alloy matrix. The heating and cooling curves of $\mathrm{Ag} / \mathrm{Gc}$ composite do not indicate thermal effects apart from the ones related to melting and solidification. Therefore, it can be stated that the
Table 1 Phase composition of studied composites

\begin{tabular}{lllll}
\hline Denotation & $\begin{array}{l}\text { Matrix chemical com- } \\
\text { position, at./\% }\end{array}$ & Particles type & $\begin{array}{l}\text { Average particle } \\
\text { diameter/ } \mu \mathrm{m}\end{array}$ & $\begin{array}{l}\text { Volume fraction } \\
\text { of the reinforcing } \\
\text { phase/\% }\end{array}$ \\
\hline $\mathrm{Ag} / \mathrm{Al}_{2} \mathrm{O}_{3}$ & $\mathrm{Ag}-95, \mathrm{Al}-2.5$ & $\mathrm{Al}_{2} \mathrm{O}_{3}$ & $25-50$ & 10 \\
$\mathrm{Ag} / \mathrm{SiC}$ & $\mathrm{Si}-1, \mathrm{Mg}-1$ & $\mathrm{SiC}$ & $20-40$ & 10 \\
$\mathrm{Ag} / \mathrm{Gc}$ & $\mathrm{Cu}+\mathrm{Ni}+\mathrm{Ti}-0.5$ & $\mathrm{Gc}^{\mathrm{a}}$ & $25-50$ & 10 \\
\hline
\end{tabular}

${ }^{\mathrm{a}}$ Glassy carbon 

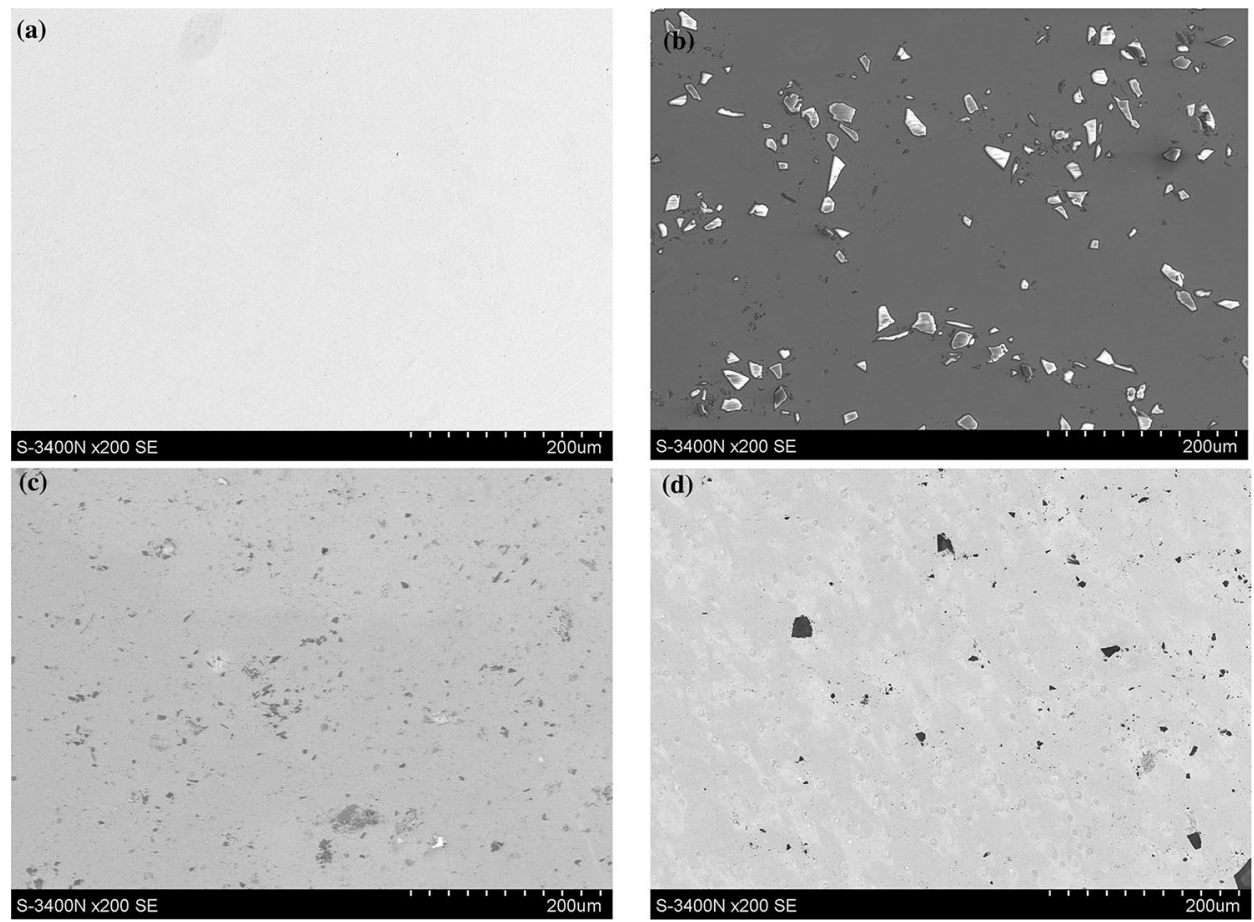

Fig. 1 Microstructure of studied materials: a matrix alloy, b Ag/ $\mathrm{Al}_{2} \mathrm{O}_{3}$ composite, $\mathbf{c} \mathrm{Ag} / \mathrm{SiC}$ composite, $\mathbf{d} \mathrm{Ag} / \mathrm{Gc}$ composite

$\mathrm{Ag} / \mathrm{Gc}$ composite is stable with temperature increase until melting temperature.

Significant influence of reinforcing phase on melting temperature was stated. Table 2 presents summary of melting temperature results considering melting of pure silver. The lowest melting temperature was registered for $\mathrm{Ag} / \mathrm{Gc}$ composite, and it was $647^{\circ} \mathrm{C}$. In order to explain this phenomenon, it was decided to perform an additional energy dispersive X-ray spectroscopy (EDS) analysis. The results are presented in Fig. 3. The EDS analysis shows that chemical composition of the matrix of individual composites differs near the reinforcement. Introduction of reinforcing particles into the alloy affects the kinetics of crystallization processes. Surface energy changes, and reinforcing particles also become crystal nucleus [25]. The technology of manufacturing MMCp composites described in this work requires introduction of reinforcing particles into an alloy that provides wettability. The obtained suspension is introduced into a modified silver alloy. In addition, composites were subjected to extrusion with KOBO method. For this reason, chemical composition of the matrix is developed, which makes it difficult to clearly determine the reactions taking place in tested composites.
Figure 4 shows the results of dilatometric measurements. Linear coefficient of thermal expansion of the particular reinforcing particles is several times smaller than in the case of pure silver $\left(18 \mathrm{~K}^{-1} \times 10^{-6}\right)$, and is, respectively, about $4.5 \mathrm{~K}^{-1} \times 10^{-6}$ for $\mathrm{Al}_{2} \mathrm{O}_{3}, 3.8 \mathrm{~K}^{-1} \times 10^{-6}$ for $\mathrm{SiC}$, and $3.7 \mathrm{~K}^{-1} \times 10^{-6}$ for glassy carbon (all values for temperature $20{ }^{\circ} \mathrm{C}$ ). For this reason, the effect of thermal expansion of particles in the tested composites can be considered negligible. On the other hand, the lowest values were obtained for composite reinforced with $\mathrm{Al}_{2} \mathrm{O}_{3}$ particles. A similar phenomenon was observed in aluminum-based alloys reinforced with $\mathrm{Al}_{2} \mathrm{O}_{3}$. In the paper [25], it was showed that dimensional changes of samples and the shape of dilatometric curves are significantly influenced by the size and content of reinforcing particles. It was noted that at temperature $430{ }^{\circ} \mathrm{C}$, deviation from tangent according to a heating direction can be correlated with polymorphic transition occurring in $\mathrm{Al}_{2} \mathrm{O}_{3}$. In the case of composite reinforced with $\mathrm{SiC}$ and glassy carbon, linear coefficient of thermal expansion was close to the values obtained for pure silver. It implies that in all examined composites, the presence of reinforcing particles did not influence negatively on the value of linear thermal expansion coefficient, and clearly lowered it in the case 
(a)

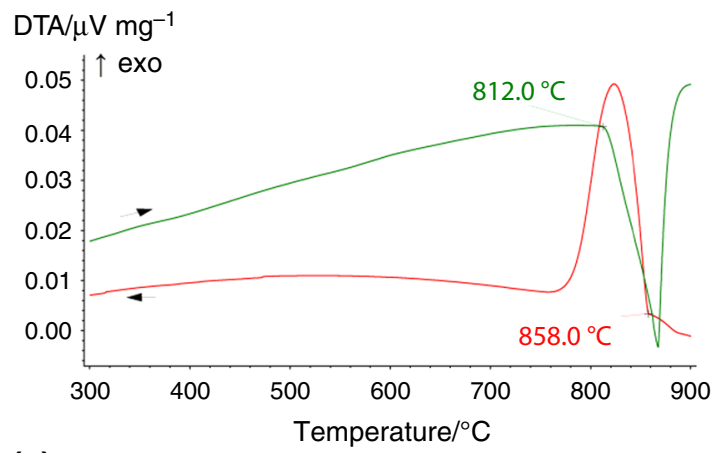

(c)

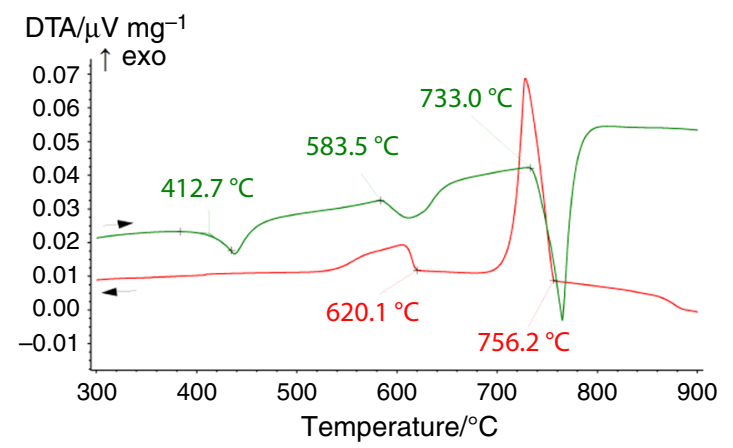

(b)

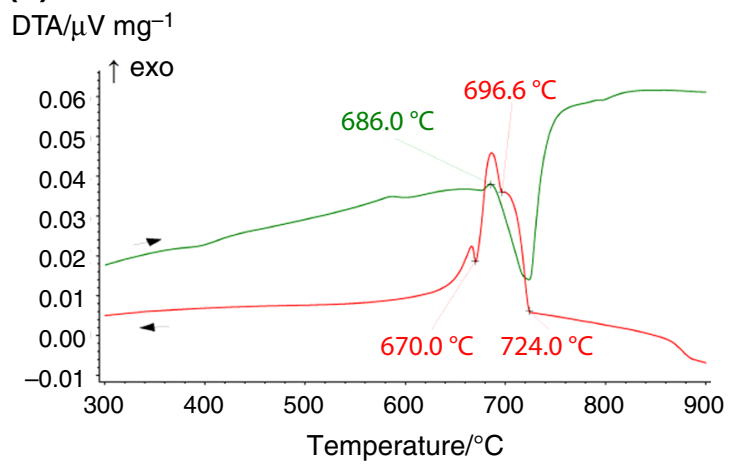

(d)

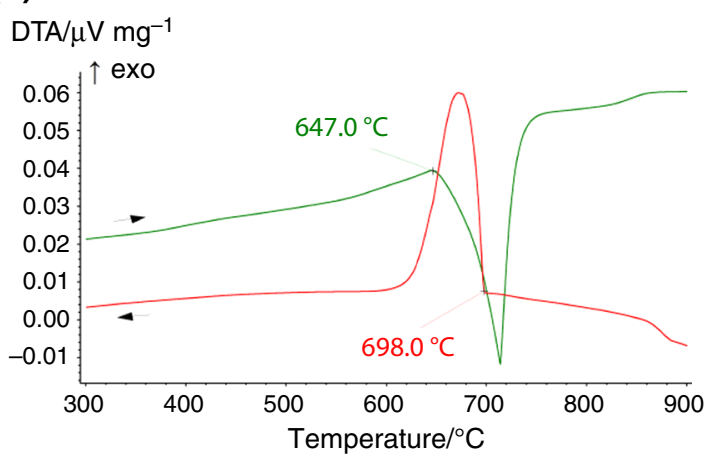

Fig. 2 DTA curves registered during melting and cooling of: a matrix alloy, b $\mathrm{Ag} / \mathrm{Al}_{2} \mathrm{O}_{3}$ composite, $\mathbf{c} \mathrm{Ag} / \mathrm{SiC}$ composite, $\mathbf{d} \mathrm{Ag} / \mathrm{Gc}$ composite

Table 2 Melting temperature of pure silver, matrix alloy, and composites determined during DTA thermal analysis

\begin{tabular}{ll}
\hline Material & $\begin{array}{l}\text { Melting } \\
\text { temperature } /{ }^{\circ} \mathrm{C}\end{array}$ \\
\hline $\mathrm{Ag}$ & 961.8 \\
Matrix alloy & 812.0 \\
$\mathrm{Ag} / \mathrm{Al}_{2} \mathrm{O}_{3}$ & 686.0 \\
$\mathrm{Ag} / \mathrm{SiC}$ & 733.0 \\
$\mathrm{Ag} / \mathrm{Gc}$ & 647.0 \\
\hline
\end{tabular}

of composite reinforced with particles $\mathrm{Al}_{2} \mathrm{O}_{3}$. It is worth to notice that melting effects in the composite sample $\mathrm{Ag} / \mathrm{Gc}$ at maximum temperature of dilatometric measurement $650{ }^{\circ} \mathrm{C}$ were not found. The onset temperature of endothermic peak is very close and equals $647^{\circ} \mathrm{C}$ in this case. The explanation should be sought again in complexity of matrix alloy. In comparison with pure metals, melting of alloys is accompanied by a gentler slope of the DTA plot, which implies prior melting of minor quantities of low melting phases.
The results of thermal expansion measurements were used to calculate material density as function of temperature based on formula:

$\rho(T)=\frac{\rho_{\mathrm{o}}}{\left(1+\frac{\Delta L}{L_{\mathrm{o}}}(T)\right)^{3}}$

where $\rho_{\mathrm{o}}$-apparent density of material (determined using Archimedes law), $L_{\mathrm{o}}$-initial sample length, $\Delta L$ -an increase in sample length with temperature range $\Delta T=T_{\mathrm{k}}-T_{\mathrm{o}}, T_{\mathrm{k}}$-initial temperature of measurement, $T_{\mathrm{o}}$ -final temperature of measurement. The results are compiled in Table 3.

Figure 5 shows measurement results of thermal diffusivity $\alpha$. The highest values were obtained for composite $\mathrm{Ag} /$ $\mathrm{Al}_{2} \mathrm{O}_{3}$, and the lowest for $\mathrm{Ag} / \mathrm{Gc}$. In both cases, the decrease in thermal diffusion value is distinct for temperature $650{ }^{\circ} \mathrm{C}$. It may be related to proximity to melting point. However, for $\mathrm{Ag} / \mathrm{SiC}$ composite, the increase in thermal diffusion at 
(a)

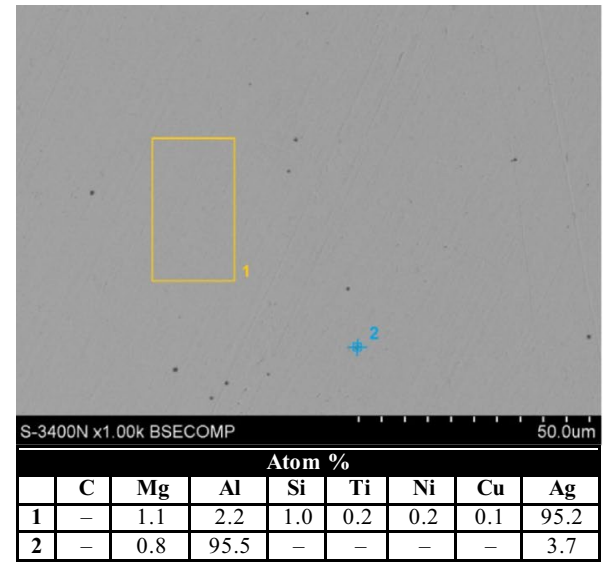

(c)

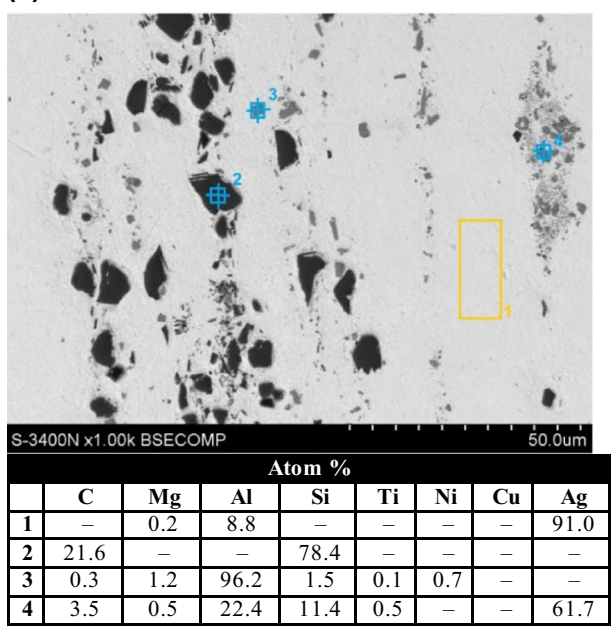

(b)

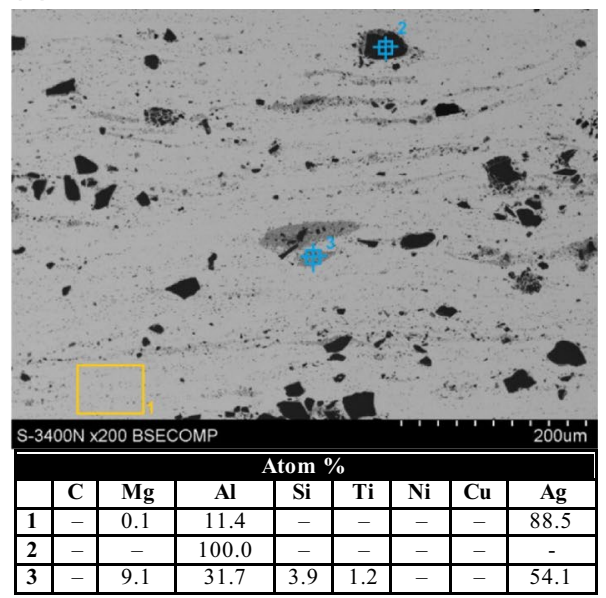

(d)

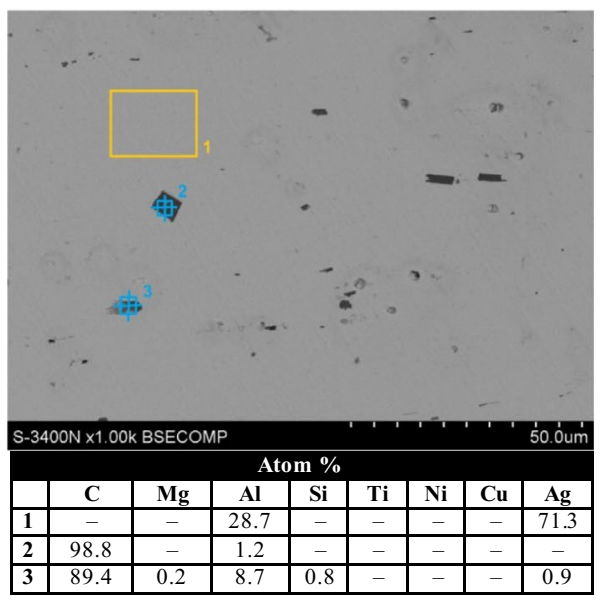

Fig. 3 Results of EDS analysis: a matrix alloy, b Ag/Al $\mathrm{O}_{3}$ composite, $\mathbf{c} \mathrm{Ag} / \mathrm{SiC}$ composite, $\mathbf{d} \mathrm{Ag} / \mathrm{Gc}$ composite

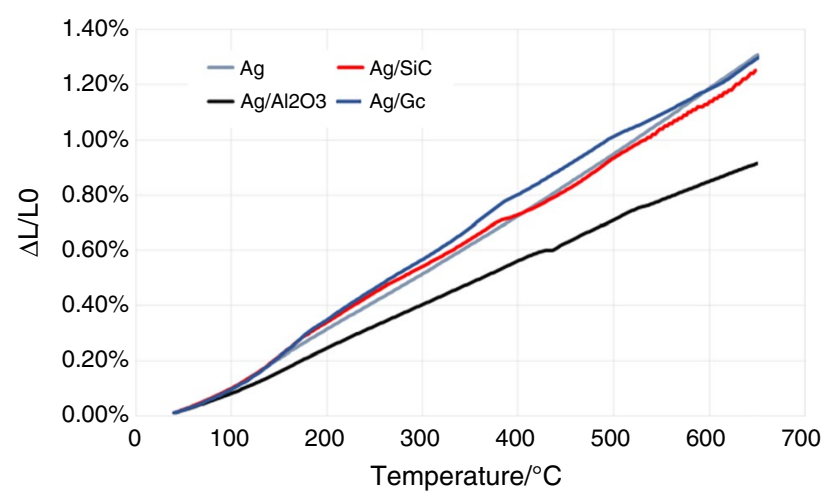

Fig. 4 Dependence of relative elongation from temperature of composites in relation to silver

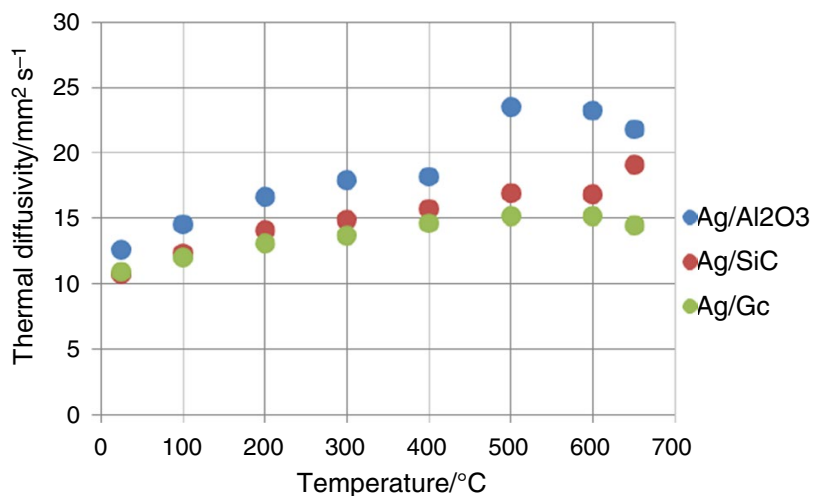

Fig. 5 Thermal diffusivity of studied composites 
Table 3 Calculated values of composites density in relation to temperature

\begin{tabular}{llll}
\hline & $\mathrm{Ag} / \mathrm{Al}_{2} \mathrm{O}_{3}$ & $\mathrm{Ag} / \mathrm{SiC}$ & $\mathrm{Ag} / \mathrm{Gc}$ \\
\hline$\rho_{\mathrm{o}} / \mathrm{kg} \mathrm{m}^{-3}$ & 7525 & 8156 & 7164 \\
\hline Temperature $/{ }^{\circ} \mathrm{C}$ & $\rho(T) / \mathrm{kg} \mathrm{m}^{-3}$ & $\rho(T) / \mathrm{kg} \mathrm{m}^{-3}$ & $\rho(T) / \mathrm{kg} \mathrm{m}^{-3}$ \\
\hline 100 & 7503 & 8132 & 7143 \\
200 & 7454 & 8074 & 7090 \\
300 & 7412 & 8025 & 7044 \\
400 & 7376 & 7981 & 6995 \\
500 & 7335 & 7932 & 6951 \\
600 & 7294 & 7884 & 6916 \\
\hline
\end{tabular}

Table 4 Thermal conductivity of studied composites

\begin{tabular}{llll}
\hline Temperature $/{ }^{\circ} \mathrm{C}$ & \multicolumn{3}{l}{ Thermal conductivity $/ \mathrm{W} \mathrm{m}^{-1} \mathrm{~K}^{-1}$} \\
\cline { 2 - 4 } & $\mathrm{Ag} / \mathrm{Al}_{2} \mathrm{O}_{3}$ & $\mathrm{Ag} / \mathrm{SiC}$ & $\mathrm{Ag} / \mathrm{Gc}$ \\
\hline 25 & 27.414 & 27.414 & 21.930 \\
100 & 33.373 & 33.373 & 26.272 \\
200 & 40.765 & 40.765 & 31.698 \\
300 & 43.918 & 43.918 & 35.208 \\
400 & 46.267 & 46.267 & 39.253 \\
500 & 61.631 & 61.631 & 42.481 \\
600 & 61.282 & 61.282 & 42.246 \\
650 & 57.550 & 57.550 & 40.506 \\
\hline
\end{tabular}

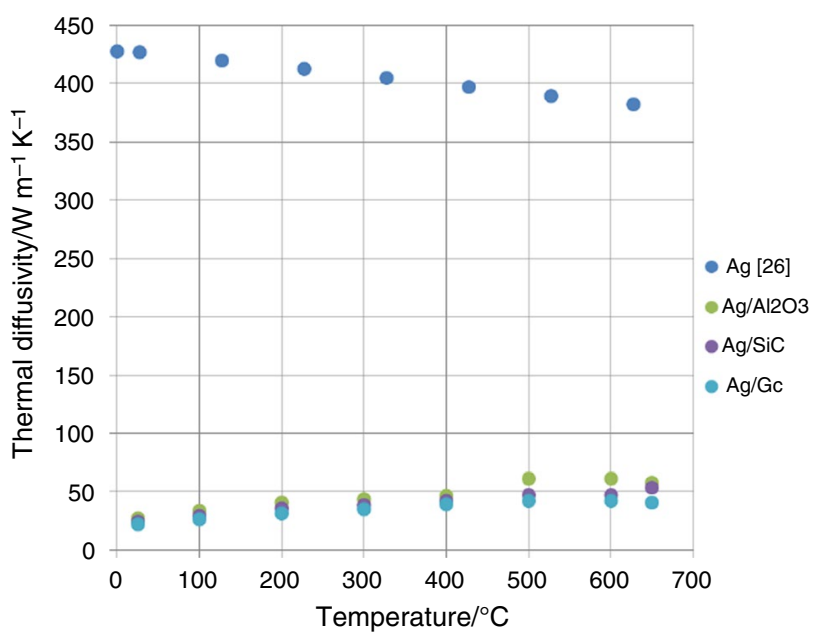

Fig. 6 Thermal conductivity coefficient of studied composites and pure silver temperature $650{ }^{\circ} \mathrm{C}$ is present, which may result from phase transition noted during thermal analysis. The distinct increase in thermal diffusion for temperature between 400 and $500{ }^{\circ} \mathrm{C}$ for $\mathrm{Ag} / \mathrm{Al}_{2} \mathrm{O}_{3}$ might prove the presence of polymorphic phase $\mathrm{Al}_{2} \mathrm{O}_{3}$, which was not registered on DTA curves due to low sensitivity, whereas, occurs on dilatometric curve.

Thermal conductivity coefficient $\lambda$ of examined composites was determined by substituting to formula (1) all obtained results with values of specific heat $C_{\mathrm{P}}$, determined based on thermodynamic data of pure components based on mixing principle:

$C p=\sum_{i=1}^{n} C p_{\mathrm{i}} \cdot V_{\mathrm{i}}$

where $C p_{\mathrm{i}}$-specific heat of the component, $V_{\mathrm{i}}$-volume fraction of the component. The results are combined in Table 4; Fig. 6 compares it with value of coefficient $\lambda$ for pure silver [26]. The value of thermal conductivity coefficient $\lambda$ in the tested composites increases with temperature, however, it is few times lower than that of pure silver. It is related to not only the presence of reinforcing phases of $\mathrm{Al}_{2} \mathrm{O}_{3}, \mathrm{SiC}$ and glassy carbon, however, is also connected with chemical composition of matrix alloy, which apart from silver contains $5 \%$ of other alloying components.

\section{Conclusions}

1. The suspension method was used for preparation of MMCp composites with silver alloy matrix, presented in this paper, enables wetting of $\mathrm{Al}_{2} \mathrm{O}_{3}$ and $\mathrm{SiC}$ particles by liquid silver. 
2. Differential thermal analysis indicated that the presence of reinforcing particles leads to lowering of melting temperature of studied composites due to affect of kinetics and crystallization processes by particles. In the case of composite reinforced with glassy carbon, it is up to $150{ }^{\circ} \mathrm{C}$ with regards to alloy matrix.

3. The studied composites indicate thermal stability in the range up to $650{ }^{\circ} \mathrm{C}$. The only exception is composite reinforced with $\mathrm{SiC}$ particles, for which, the distinct thermal effects related to phase transition below this temperature were present.

4. The presence of a reinforcing phase in form of particles has an influence on thermal expansion of composites with silver alloy matrix. Aluminum oxide particles clearly reduce thermal expansion as opposed to silicon carbide and glassy carbon particles, which slightly changes it in relation to pure silver.

5. Matrix alloy composition and the presence of a reinforcing phase in form of $\mathrm{Al}_{2} \mathrm{O}_{3}, \mathrm{SiC}$ and $\mathrm{Gc}$ particles affects thermal conductivity of the composites. With addition of reinforcing particles, there is approximately eight times decrease in thermal conductivity in relation to pure silver.

Acknowledgements Silesian University of Technology (Faculty of Materials Engineering), supported this work as a part of Statutory Research BK-200/RM0/2020 (11/990/BK_20/0074).

Open Access This article is licensed under a Creative Commons Attribution 4.0 International License, which permits use, sharing, adaptation, distribution and reproduction in any medium or format, as long as you give appropriate credit to the original author(s) and the source, provide a link to the Creative Commons licence, and indicate if changes were made. The images or other third party material in this article are included in the article's Creative Commons licence, unless indicated otherwise in a credit line to the material. If material is not included in the article's Creative Commons licence and your intended use is not permitted by statutory regulation or exceeds the permitted use, you will need to obtain permission directly from the copyright holder. To view a copy of this licence, visit http://creativecommons.org/licenses/by/4.0/.

\section{References}

1. Miracle DB. Metal matrix composites-from science to technological significance. Compos Sci Technol. 2005;65:2526-40.

2. Rosso M. Ceramic and metal matrix composites: routes and properties. J Mater Process Technol. 2006;175:364-75.

3. Kaczmar JW, Pietrzak K, Włosiński W. The production and application of metal matrix composite materials. J Mater Process Technol. 2000;106:58-67.

4. Macke A, Schultz BF, Rohatgi P. Metal matrix composites. Adv Mater Process. 2012;3:19-23.

5. Rawal SP. Metal-matrix composites for space applications. JOM. 2001;53:14-7.
6. Dolata AJ, Dyzia M, Walke W. Influence of particles type and shape on the corrosion resistance of aluminium hybrid composites. Solid State Phenom. 2012;191:81-7.

7. Prasad SV, Asthana R. Aluminum metal-matrix composites for automotive applications: tribological considerations. Tribol Lett. 2004;17:445-53.

8. Smith RJ, Lewi GJ, Yates DH. Development and application of nickel alloys in aerospace engineering. Aircr Eng Aerosp Technol. 2001;73:138-47.

9. Bochenek K, Basista M. Advances in processing of NiAl intermetallic alloys and composites for high temperature aerospace applications. Prog Aerosp Sci. 2015;79:136-46.

10. Sharma SC, Girish BM, Kamath R, Satish BM. Graphite particles reinforced ZA-27 alloy composite materials for journal bearing applications. Wear. 1998;219:162-8.

11. Abyzow AM, Kidalov SV, Shakhov FM. High thermal conductivity composite of diamond particles with tungsten coating in a copper matrix for heat sink application. Appl Therm Eng. 2012;48:72-80.

12. Findik F, Uzun H. Microstructure, hardness and electrical properties of silver-based refractory contact materials. Mater Des. 2003;24:489-92.

13. Slade PG. Electrical contacts: principles and applications. 2nd ed. Boca Raton: CRC Press; 2017.

14. Wieczorek J, Oleksiak B, Łabaj J, Węcki B, Mańka M. Silver matrix composites-structure and properties. Arch Metall Mater. 2016;61:323-8.

15. Tan MJ, Zhang X. Powder metal matrix composites: selection and processing. Mater Sci Eng A. 1998;244:80-5.

16. Koli DK, Agnihotri G, Purohit R. Properties and characterization of $\mathrm{Al}-\mathrm{Al}_{2} \mathrm{O}_{3}$ composites processed by casting and powder metallurgy routes (review). IJLTET. 2013;2:486-96.

17. Dolata-Grosz A, Formanek B, Śleziona J, Wieczorek J. Al-FeAlTiAl- $\mathrm{Al}_{2} \mathrm{O}_{3}$ composite with hybrid reinforcement. J Mater Process Technol. 2005;162:33-8.

18. Śleziona J. Podstawy technologii kompozytów. Gliwice: Wydawnictwo Politechniki Śląskiej; 1998.

19. Clyne TW, Withers PJ. An introduction to metal matrix composites. Cambridge: Cambridge University Press; 1993.

20. Wieczorek J, Śleziona J, Dolata-Grosz A. Kompozyty Ag cząstki ceramiczne otrzymywane technologiami ciekło-fazowymi. Archiwum Odlewnictwa. 2006;6:311-6.

21. Prabu BS, Karunamoorthy L, Kathiresan S, Mohan B. Influence of stirring speed and stirring time on distribution of particles in cast metal matrix composite. J Mater Process Technol. 2006;171:268-73.

22. Jian-Guo Li. Wettability of silicon carbide by liquid silver and binary silver-silicon alloy. Mater Lett. 1994;18:291-8.

23. Nogi $\mathrm{K}$, Ogino K. Wettability of $\mathrm{SiC}$ by liquid pure metals. Trans Jpn Inst Met. 1988;29:742-7.

24. Nayeb-Hashemi AA, Clark JB. The Ag-Mg (silver-magnesium) system. Bull Alloy Phase Diagr. 1984;5:348.

25. Dudyk M. Crystallization and thermal expansion of alloys and silumine composites. Archiwum Oldewnictwa. 2006;6:164-9.

26. Touloukian YS, Powell RW, Ho CY, Klemens PG. Thermophysical properties of matter-the TPRC data series. Volume 1 . Thermal conductivity - metallic elements and alloys. Data book. Fort Belvoir: Defense Technical Information Center; 1970.

Publisher's Note Springer Nature remains neutral with regard to jurisdictional claims in published maps and institutional affiliations. 